\title{
The intergenerational transmission of family meal practices: a mixed-methods study of parents of young children
}

\author{
Katie A Loth ${ }^{1, *}$, Marc James A Uy ${ }^{1}$, Megan R Winkler ${ }^{2}$, Dianne Neumark-Sztainer ${ }^{2}$, \\ Jennifer Orlet Fisher ${ }^{3}$ and Jerica $M$ Berge ${ }^{1}$ \\ 'Department of Family Medicine and Community Health, University of Minnesota, 717 Delaware Street SE \#420, \\ Minneapolis, MN 55414, USA: ${ }^{2}$ Division of Epidemiology and Community Health, School of Public Health, \\ University of Minnesota, Minneapolis, MN, USA: ${ }^{3}$ Department of Social and Behavioral Sciences, College of Public \\ Health, Temple University, Philadelphia, PA, USA
}

Submitted 24 July 2018: Final revision received 30 October 2018: Accepted 23 November 2018: First published online 8 February 2019

\begin{abstract}
Objective: The current mixed-methods study explored qualitative accounts of prior childhood experiences and current contextual factors around family meals across three quantitatively informed categories of family meal frequency patterns from adolescence to parenthood: (i) 'maintainers' of family meals across generations; (ii) 'starters' of family meals in the next generation; and (iii) 'inconsistent' family meal patterns across generations.

Design: Quantitative survey data collected as part of the first (1998-1999) and fourth (2015-2016) waves of the longitudinal Project EAT (Eating and Activity in Adolescents and Young Adults) study and qualitative interviews conducted with a subset ( $n$ 40) of Project EAT parent participants in 2016-2017.

Setting: Surveys were completed in school (Wave 1) and online (Wave 4); qualitative interviews were completed in-person or over the telephone.

Participants: Parents of children of pre-school age ( $n 40)$ who had also completed Project EAT surveys at Wave 1 and Wave 4.

Results: Findings revealed salient variation within each overarching theme around family meal influences ('early childhood experiences', 'influence of partner', 'household skills' and 'family priorities') across the three intergenerational family meal patterns, in which 'maintainers' had numerous influences that supported the practice of family meals; 'starters' experienced some supports and some challenges; and 'inconsistents' experienced many barriers to making family meals a regular practice.

Conclusions: Family meal interventions should address differences in cooking and planning skills, aim to reach all adults in the home, and seek to help parents who did not eat family meals as a child develop an understanding of how and why they might start this tradition with their family.
\end{abstract}

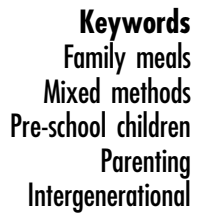

Over the past decade, research has shown that family meals are protective against poor dietary intake ${ }^{(1-5)}$, unhealthy weight-related outcomes (e.g. excessive weight gain, disordered eating behaviours) ${ }^{(5-17)}$, substance use $^{(18,19)}$ and poor psychosocial outcomes in children, adolescents and young adults ${ }^{(18,20,21)}$. Researchers posit that eating together yields both physical and psychosocial benefits for youths and adults alike by offering a daily opportunity for healthful eating and connection between family members ${ }^{(17,22,23)}$. Given existing findings which strongly suggest that family meals can serve to protect youths from a number of harmful health-related outcomes, participation in regular family meals has been recommended by several prominent organizations, associations and researchers ${ }^{(24-28)}$.

Unfortunately, despite numerous known health benefits and widespread public health messaging informing families of the importance of eating regular family meals, many families are not eating together; data suggest that the frequency of family meal consumption has decreased over time, particularly among low-income families ${ }^{(29,30)}$. In an effort to guide the development of interventions aimed at increasing the number of families who engage in regular family meals, it is important to explore mechanisms that may lead to the intergenerational transmission of family meals or changes in patterns 
across generations ${ }^{(31)}$. Researchers have begun to explore potential mechanisms by which the routine of eating family meals is passed between generations ${ }^{(32,33)}$. A study by Watts et al., which utilized data collected as a part of the ongoing Project EAT (Eating and Activity in Adolescents and Young Adults) cohort study, found that frequency of family meals and the idea that family meals were 'expected' during adolescence were associated with family meal frequency during early parenthood ${ }^{(32)}$. Using the same data set, Berge et al. examined intergenerational transmission of regular family meals from adolescence into parenthood; results indicated that young adult parents who reported having regular family meals as an adolescent and as a parent ('maintainers'), or who started having regular family meals with their own families ('starters'), reported more healthful dietary intake, weight-related behaviours and psychosocial outcomes compared with young adults who never reported having regular family meals ('nevers') ${ }^{(33)}$. A retrospective study by Friend et al. found that recalling frequent family meals during childhood was associated with engaging in family meals as a parent, as well as having more family meal routines and higher expectations for their family meals with their current family ${ }^{(34)}$. Overall, qualitative work exploring intergenerational family meal transmission has found that parents' childhood mealtime experiences, good and bad, impact their choices about how to engage in mealtimes with their own children; a common theme across several studies was that parents desire to improve upon their own eating experience to make things better for their child ${ }^{(35-37)}$. Taken together, these quantitative and qualitative findings suggest that a parent's own childhood experience with family meals has an impact on the routines and expectations he/she has for meals with his/her own family.

Using a subset of the Project EAT parent sample, the present study sought to step beyond the field's current knowledge of intergenerational family meal transmission by using a novel mixed-methods approach to provide rich description of what may influence the transmission of family meal patterns across generations. This mixed-methods study used one-on-one interviews completed during 2016-2017 with parents of children of pre-school age (2-5 years), who also completed a survey during 2015-2016 as part of the ongoing Project EAT cohort study, to explore the similarities and differences among parents' qualitative accounts of prior childhood experiences and current contextual factors around family meals across quantitatively informed categories of family meal frequency patterns from childhood to now as a parent. By better understanding the reasons why certain parents maintain their parents' family meal practices and others may diverge, results from the study may help to identify relevant opportunities for interventions that support all families in positive family meal experiences.

\section{Methods}

\section{Study participants}

Participants in the current mixed-methods study were Project EAT participants who completed both (i) a selfreport survey at Wave 1 (1998-1999; EAT-I) and Wave 4 (2015-2016; EAT-IV) of Project EAT and (ii) a one-on-one interview as part of an ancillary study (i.e. Child Feeding Study) in 2016-2017 with Project EAT parents of children aged 2-5 years old. Project EAT is a longitudinal study on eating and weight-related health during the transition from adolescence to young adulthood $^{(32,38)}$, and in 2016-2017, an ancillary qualitative study was conducted to further explore parents' experiences of feeding their pre-school child and the factors influencing the choices they made about feeding. Parents of children of pre-school age were targeted in the ancillary study as both parents and the home environment are a primary influence for children in this young age group. The participant sample for the current study includes forty parents. Figure 1 presents details on data collection and the analysis timeline.

\section{Participant recruitment}

Project EAT study participants were recruited as students ( $n$ 4746) in 1998-1999 from thirty-one public middle and high schools in Minneapolis-Saint Paul, MN, USA. Students completed self-report surveys and anthropometric measures during selected health/physical education classes. In 2015-2016, all participants in the original sample who could be contacted were invited to complete the EAT-IV survey (1830 completed the survey), which was designed to follow up on the participants as they were progressing through young adulthood at a time of life when many participants would become parents. In 20162017, a convenience sample of EAT-IV parent participants was then recruited to participate in the ancillary Child Feeding Study. Eligibility criteria included having at least one child aged 2-5 years who lived with them at least $50 \%$ of the time at the time of the EAT-IV survey. Participants meeting these criteria ( $n$ 492) were then invited by email to participate in a study of qualitative interviews to learn more about parents' experiences feeding their pre-school aged child. Participants were recruited in randomly selected batches of twenty parents and recruitment ended when theoretical saturation was reached ${ }^{(39,40)}$. Participant demographic characteristics are included in Table 1.

\section{Data collection}

\section{Quantitative}

At EAT-I, participants self-reported demographic information on their sex, age and ethnicity/race. At EAT-IV, participants self-reported their income, employment status and educational attainment, in addition to the number of children they have, their ages and their current custodial 


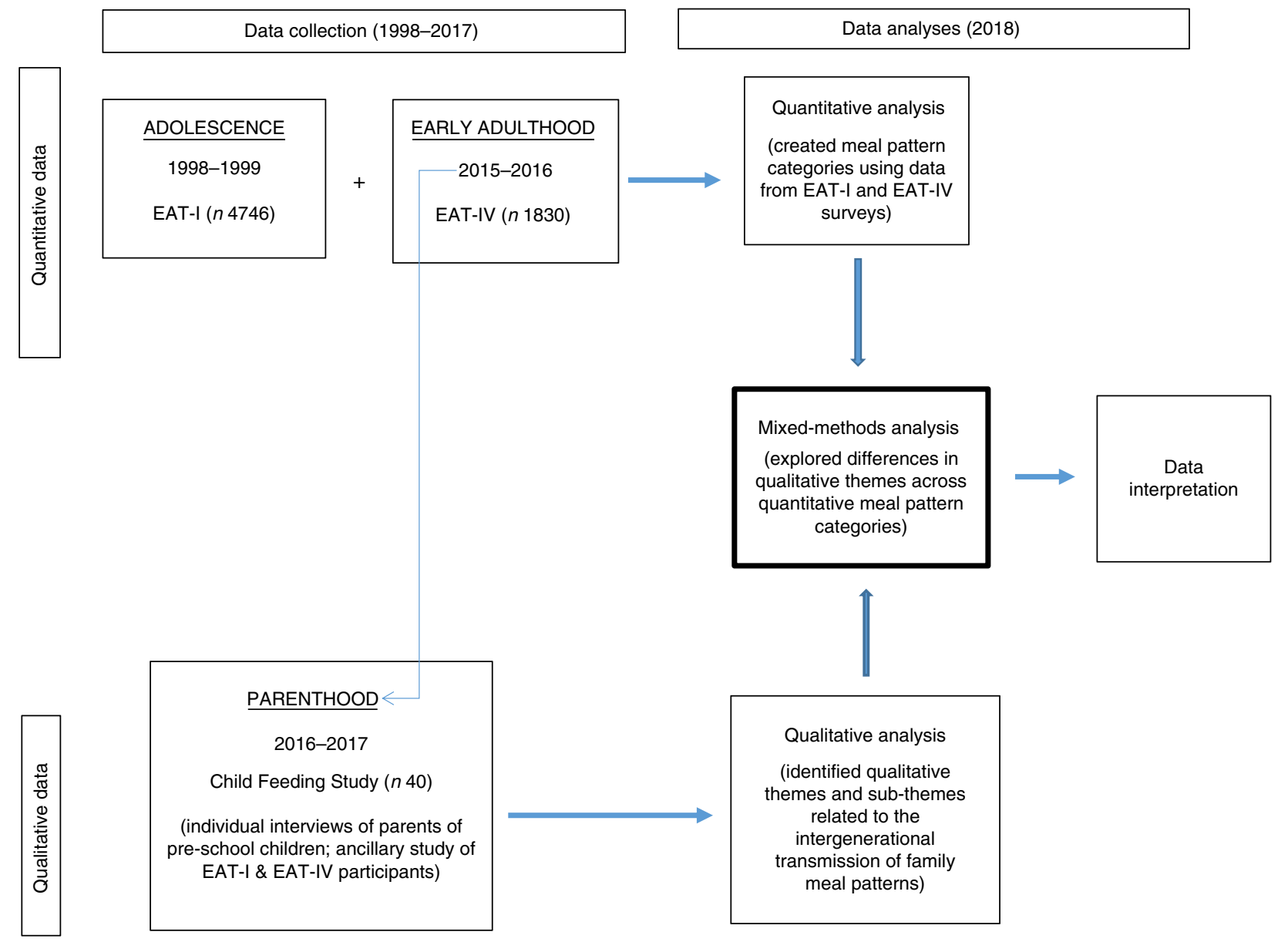

Fig. 1 (colour online) Data collection and analysis flowchart (EAT-I, wave 1 of Project EAT; EAT-IV, wave 4 of Project EAT; Project EAT, Eating and Activity in Adolescents and Young Adults)

arrangement. At both time points participants reported family meal frequency by responding to the following question: 'During the past seven days, how many times did all, or most, of your family living in your house eat a meal together?' Response options included: 'never', '1-2 times', '3-4 times', '5-6 times', ' 7 times' and 'more than 7 times' (test-retest: EAT-I, $r=0 \cdot 70$; EAT-IV, $r=0 \cdot 64$ ). Responses to these questions were used to categorize participants into an intergenerational family meal pattern trajectory; the categorization scheme utilized was based on previous research conducted by Berge et al. (details below) ${ }^{(33)}$.

\section{Qualitative}

The research team conducting the parent interviews comprised one faculty member and three graduate research assistants. The research team members were between the ages of 20 and 40 years, and represent a combination of Caucasian, Hispanic and Asian racial/ethnic groups. Before data collection, a series of research team meetings were held where research team members were trained in qualitative data collection methods ${ }^{(41)}$ and standardized interview protocols ${ }^{(42)}$; to improve reliability and consistency of interview methods, research assistants conducted several practice interviews and observed at least one participant interview (conducted by K.A.L.) prior to conducting interviews independently.

Semi-structured interview guides were used and questions covered a range of topics related to child feeding and weight-related behaviours. Questions specific to the current analysis of intergenerational transmission of family meal routines (Table 2) were based on: (i) Family Systems Theory tenets regarding intergenerational transmission of family patterns/practices ${ }^{(43)}$; (ii) recommendations from the literature to explore intergenerational transmission of mealtime practices $^{(31)}$; and (iii) gaps in the extant literature on family meal routines and child feeding practices. Specific interview questions explored parents' family meal practices when they were children; what practices they had transmitted to their own children; and the role of their partner and their partner's upbringing in their current family meal practices. The overarching goal of these questions was to deepen our understanding of what might influence the intergenerational transmission of family meal patterns. The interview guide was first piloted with two content area experts, three graduate students and four parents of children aged $2-5$ years to make sure questions were clear, elicited in-depth discussion and were acceptable to participants; feedback from pilot 
Table 1 Intergenerational family meal patterns by demographic characteristics among parents of children of pre-school age; a subset of Project EAT (Eating and Activity in Teens and Young Adults), 2016-2017

\begin{tabular}{|c|c|c|c|c|c|c|}
\hline \multirow[b]{3}{*}{ Demographic characteristic } & \multicolumn{6}{|c|}{ Intergenerational family meal pattern } \\
\hline & \multicolumn{2}{|c|}{$\begin{array}{l}\text { 'Maintainer' } \\
(n \text { 9) }\end{array}$} & \multicolumn{2}{|c|}{$\begin{array}{l}\text { 'Starter' } \\
(n \text { 24) }\end{array}$} & \multicolumn{2}{|c|}{$\begin{array}{l}\text { 'Inconsistent' } \\
(n \text { 7) }\end{array}$} \\
\hline & Mean or $\%$ & SD or $n$ & Mean or $\%$ & SD or $n$ & Mean or \% & SD or $n$ \\
\hline Age (years), mean and SD & $31 \cdot 2$ & $1 \cdot 3$ & $31 \cdot 6$ & $1 \cdot 2$ & $31 \cdot 3$ & $1 \cdot 3$ \\
\hline \multicolumn{7}{|l|}{ Gender, $\%$ and $n$} \\
\hline Male & 33.3 & 3 & $20 \cdot 8$ & 5 & $42 \cdot 9$ & 3 \\
\hline Female & $66 \cdot 7$ & 6 & 79.2 & 19 & $57 \cdot 1$ & 4 \\
\hline \multicolumn{7}{|l|}{ Race/ethnicity, \% and $n$} \\
\hline White & $66 \cdot 7$ & 6 & 83.3 & 20 & $100 \cdot 0$ & 7 \\
\hline Parents of colour & $33 \cdot 3$ & 3 & $16 \cdot 7$ & 4 & 0.0 & 0 \\
\hline \multicolumn{7}{|l|}{ Income, $\%$ and $n$} \\
\hline$<$ SUS 50000 & $33 \cdot 3$ & 3 & $16 \cdot 6$ & 4 & $14 \cdot 3$ & 1 \\
\hline \$US 50 000-99999 & $33 \cdot 3$ & 3 & $45 \cdot 8$ & 11 & $14 \cdot 3$ & 1 \\
\hline$\geq$ \$US 100000 & $33 \cdot 3$ & 3 & 37.5 & 9 & $20 \cdot 8$ & 5 \\
\hline \multicolumn{7}{|l|}{ Employment status, $\%$ and $n$} \\
\hline Working full-time & $77 \cdot 8$ & 7 & $70 \cdot 8$ & 17 & $85 \cdot 7$ & 6 \\
\hline Working part-time & $22 \cdot 2$ & 2 & $16 \cdot 7$ & 4 & 0.0 & 0 \\
\hline Stay-at-home caregiver & 0.0 & 0 & $12 \cdot 5$ & 3 & $14 \cdot 3$ & 1 \\
\hline \multicolumn{7}{|l|}{ Educational attainment, $\%$ and $n$} \\
\hline High school or less & 0.0 & 0 & 4.2 & 1 & $8 \cdot 3$ & 2 \\
\hline Technical school or associate's degree & $11 \cdot 1$ & 1 & $20 \cdot 8$ & 5 & 8.3 & 2 \\
\hline Bachelor's degree & $66 \cdot 7$ & 6 & $50 \cdot 0$ & 12 & $14 \cdot 3$ & 1 \\
\hline Graduate degree & $22 \cdot 2$ & 2 & $25 \cdot 0$ & 6 & 8.3 & 2 \\
\hline \multicolumn{7}{|l|}{ Number of children, $\%$ and $n$} \\
\hline 1 & 44.4 & 4 & 8.3 & 2 & 8.3 & 2 \\
\hline 2 & $33 \cdot 3$ & 3 & $75 \cdot 0$ & 18 & $57 \cdot 1$ & 4 \\
\hline$\geq 3$ & $22 \cdot 2$ & 2 & $16 \cdot 7$ & 4 & $14 \cdot 3$ & 1 \\
\hline \multicolumn{7}{|l|}{ Relationship status, $\%$ and $n$} \\
\hline Single, casually dating & 0.0 & 0 & $12 \cdot 5$ & 3 & 0.0 & 0 \\
\hline Committed relationship & $22 \cdot 2$ & 2 & 4.2 & 1 & $14 \cdot 3$ & 1 \\
\hline Married, domestic partner & 77.8 & 7 & 83.3 & 20 & 85.7 & 6 \\
\hline
\end{tabular}

'Maintainers' $(n$ 9) reported having regular family meals both at baseline and 15-year follow-up. 'Starters' $(n 24)$ reported not having regular family meals at baseline but having regular family meals at 15-year follow-up. 'Inconsistents' $(n 7)$ reported having infrequent/irregular family meals at baseline and at 15-year follow-up (see text for details).

testing was used to modify the wording, content and order of interview questions prior to fielding.

Although interviews were semi-structured, probes were used to facilitate fuller responses to questions. Interviews ranged in length from 30 to $60 \mathrm{~min}$. The majority of interviews ( $n$ 30) took place in a private room on the university campus, while ten interviews took place over the telephone due to the participant not living locally or having other barriers to meeting in person (e.g. childcare challenges). There were no major differences between in-person interviews and phone interviews with regard to interview length and participant responses. Interviews were audio-recorded and written consent from participants was obtained before commencing the interview. All study protocols were approved by the University of Minnesota's Institutional Review Board Human Subjects Committee.

\section{Data analysis}

\section{Quantitative}

Following the approach in Berge et al., we first created a binary variable to define the regularity of family meals reported on the EAT-I (1998-1999) and at EAT-IV (20152016) surveys, with five or more family meals per week categorized as 'regular'(33). Initially, four family meal frequency patterns were created including: 'nevers', 'starters', 'stoppers' and 'maintainers'. 'Nevers' ( $n$ 4) reported not having regular family meals both at EAT-I and EAT-IV; 'starters' ( $n$ 23) reported not having regular family meals at EAT-I but having regular family meals at EAT-IV; 'stoppers' ( $n$ 3) reported having regular family meals at EAT-I but not at EAT-IV; and 'maintainers' ( $n$ 9) reported having regular family meals both at EAT-I and EAT-IV. Upon further review of participant responses, the 'never' and 'stopper' categories were collapsed and re-named 'inconsistent' because all participants reported eating at least some family meals at both time points, making 'inconsistent' a more apt description of this group. Previous research ${ }^{(33)}$ using this categorization scheme found that family meal frequency patterns over time tended to be similar across the following sociodemographic characteristics: sex, race/ ethnicity, socio-economic status and number of children living in the home; the lack of demographic differences between the 'never' and 'stopper' categories within the 
Table 2 Semi-structured interview guide

I am interested in learning more about how you feed your child and how your own childhood experiences with food and eating influence the types of things you do now with your own child. Remember, there are no right or wrong answers, please feel free to provide me with as much detail as you feel comfortable with as we work through each question.

1. To start out, can you tell me a little bit about how meals and snacks look for your child? For example, 'I am interested in learning...'

2. When do you feed your child a meal/snack?

3. Who decides what your child will eat for a meal/snack?

4. Is your child allowed to help him/herself to food without asking you first?

5. Who decides how much food your child eats for a meal/ snack?

6. What do you do if your child refuses to have certain foods put on his/her plate (or refuses to eat certain foods he/she is served)? Is this always handled in the same way or does it change?

7. How is it handled if your child says he/she is done eating/no longer hungry but there is still food left on his/her plate or you feel like he/she has not eaten enough?

8. How is it handled if your child wants more food than you put on his/her plate (or than he/she put on his/her plate)? More snack during a snack time?

9. We have talked today about many different decisions you make about how to feed your child. Are there any guidelines, rules or routines that you follow when feeding your child that $I$ did not ask about?

10. In what way, if at all, do you feel like the way meals looked for you as a child has impacted what you do with your child?

11. In what way, if at all, do you feel like the way meals looked for you as a child has impacted what you do with your child? (additional probes that touched on rules, routines, types of foods, family meals)

12. How about your partner and the way he/she was brought up do you feel like that has had any impact on what you do with your child? (additional probes that touched on rules, routines, types of foods, family meals)

13. How did it go for you and your partner to blend together the different experiences you had growing up as you developed your own family routines?

larger Project EAT sample provided additional evidence that collapsing these two categories was an acceptable approach. The current study builds on and expands this prior study by conducting an in-depth examination of parents' perspectives of what factors influenced whether they continued the family meal routines (i.e. regular or irregular family meals) experienced in adolescence now as a parent.

\section{Qualitative}

Audio-recorded interviews with parents ( $n$ 40) from the 2016-2017 ancillary study were transcribed verbatim and coded using a hybrid deductive and inductive content analysis approach ${ }^{(44,45)}$ using NVivo10 software (2014; QSR International Pty Ltd, Burlington, MA, USA). The hybrid deductive/inductive qualitative approach allowed the initial research questions to guide the development of the coding tree (deductive), while also allowing for unique data-derived concepts and themes to be identified (inductive). After an initial coding tree was created (by K.A.L.), coding of all interview transcripts was conducted by two coders (K.A.L. and M.J.A.U.) in multiple stages: (i) line-by-line coding of all interviews; and (ii) organization of codes into initial themes/sub-themes. The two coders met after each stage of coding to review all coding decisions; discrepancies revealed at each stage were discussed until agreement was reached and then both coders moved on to the next stage ${ }^{(46-48)}$.

\section{Mixed methods}

The quantitative survey data and qualitative interview data were then merged during a final stage of analysis. In particular, after the initial round of coding and theme development, qualitative data were stratified by the three quantitatively informed groups based on intergenerational family meal patterns (described above): 'maintainers' ( $n$ 9), 'starters' ( $n$ 24) and 'inconsistents' ( $n$ 7). Codes and initial themes and sub-themes were then further analysed using a matrix that facilitated comparisons across the three intergenerational family meal pattern groups. This process led to further refinement of overarching themes as well as sub-themes for each intergenerational family meal pattern group.

\section{Results}

We identified four overarching themes regarding influences on intergenerational transmission of family meals, including: (i) early experiences; (ii) influence of the partner; (iii) household skills; and (iv) parent priorities. For each of these overarching themes, sub-themes were identified within each of the intergenerational family meal pattern groups ('maintainers', 'starters', 'inconsistents'). Below, we provide a description of each overarching theme and sub-themes for each family meal pattern group along with illustrative quotes. Table 3 highlights overarching themes, sub-themes and associated quotes by intergenerational family meal pattern group.

\section{Early experiences}

The majority of participants in the 'maintainers' family meal pattern recalled family meals as being expected and reported having positive memories associated with eating family meals during childhood and adolescence. For many, these positive memories played a role in their decision to continue the tradition of family meals with their own children. For example,

'I mean, I always really enjoyed that time of like sit down and conversation, and my dad would even quiz me on like math problems, so it was kind of like an interactive time. I wouldn't say it was chaotic by any means. It was definitely like a sit-down meal, and that, to me, growing up I think was a huge - I mean, if I remember it so vividly, I would call it a 
pretty impactful moment, so that's kind of the same moments we're trying to carry forward to my kids as well.' (Father)

Participants in the 'starters' family meal pattern described having mixed memories of their early meal experiences, with some participants describing occasional meals eaten together and others not having any strong childhood memories of eating with their family. For example, one participant said,

'Growing up, I came from a family that, if we remembered to eat, it was great, but no one in my family was really big on food (or eating together).' (Mother)

Further, many participants in this group talked about having fewer opportunities to learn or practice food preparation or meal planning skills during childhood. For example,

'I've tried to change [from how things were when I was a child], because my mom was one who never meal planned, and we ate out a lot, tons. And so I'd come home from school, and I remember my mom would be standing at the pantry looking in there, being like, "What should we have for dinner?" You know, it's 4:30, and then she didn't know or she didn't have groceries, so we'd get in the car and we'd go out to eat.' (Mother)

Several families in the 'inconsistent' pattern discussed having fewer memories or less positive memories of eating family meals as a child. One participant recalled,

'So I guess I remember we [my sisters and mom] used to take turns cooking dinner or something like that, but I don't remember a lot of meals besides special occasions or holidays.' (Mother)

\section{Role of partner}

The majority of parents in the 'maintainers' pattern discussed the fact that their partners shared a similar childhood tradition of eating regular family meals, which made it easy for them to prioritize carrying forward this same tradition with their children. For example,

'We both [my wife and I] were raised in a family that always ate together. Always.' (Father)

The few participants in this pattern whose partners did not eat family meals during their childhood discussed that their partner seemed to appreciate or understand the value of family meals, despite not having engaged in them themselves. One participant described,

'I think, once we started combining our two ways of doing things when we first were married, he just kind of naturally felt more comfortable about my way of doing things, $\ldots$ and so he seemed to kind of like my way of doing things better, and so that's kind of just how we naturally fell into place before we had kids, and that has continued with the kids.' (Mother)

Several participants in the 'starter' pattern shared that it was the influence of their partner that led them to start to eat family meals, as their partner brought with them new family traditions or values around eating together. As described by one participant,

'They [husband's family] always had a really strong family base and doing - like they'd always eat together, and wash the dishes after meals. That was always their big thing. And so we [my husband and I] kind of brought that into our home and helping out afterwards and washing dishes and having the family environment is important to us.' (Mother)

Several families who were part of the 'inconsistent' family meal pattern discussed the role that work and schedule conflicts with their partner played in their inability to have consistent family meals. Some participants talked about how eating together was a priority for their family and emphasized that when their schedule allowed them to, they always took advantage by having meals with their family. For example, one participant said,

'Well, this summer I was on first shift at my work. I was able to get off at 3:00 in the afternoon, and come get the kids, and come home and make dinner, but now I've got shifted back to the second shift, so currently it's just my wife and those two at dinnertime. Sometimes I'll get home early enough, and they'll be still sitting at the table, and I'll join them, then generally all four of us around the table, trying to have a family meal, with no distractions.' (Father)

\section{Housebold skills}

Many participants across meal pattern groups discussed the impact that specific household skills had on their ability to eat home-cooked family meals. Participants in the 'maintainer' pattern noted that either they or their partner (or both) felt confident in their food preparation and meal planning skills, which made it easy for them to carry on the tradition of family meals. For example, one participant said,

'We are absolutely comfortable [cooking]. We watch cooking shows and have far too many cookbooks that we never read, and cooking emails. Yeah, we keep working on it, and we'll try something and it won't work, and we'll try it again a little bit differently the next time.' (Mother)

Participants in the 'starter' category exhibited some diversity around who possessed the household skills, but in all instances at least one of the parents had developed 


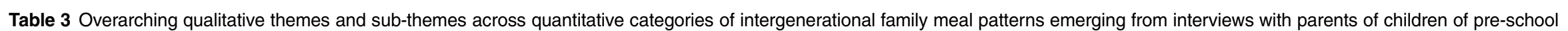
age; a subset of Project EAT (Eating and Activity in Teens and Young Adults), 2016-2017

Qualitative themes

Intergenerational family meal pattern

'Maintainers' ( $n$ 9)

Household skills

Family priorities

'Starters' (n 24)

Early experiences

Influence of partner

Household skills

Family priorities
Sub-themes

Meals were expected, routine

Positive memories of family meals

Partners shared similar tradition of eating family meals

OR

Partners appreciated the value of family meals

One or both adults felt confident in their cooking and meal planning skills

Desire to maintain tradition of family meals

Eager to prepare and serve healthier food than they ate during childhood

Mixed memories of family meals

Fewer opportunities to learn or practice food preparation or meal planning

Partner brought with them new family traditions or values around eating together Partner had cooking or meal planning skills

Developed cooking and meal preparation skills during adulthood

Making family meals a priority

Desire to do things differently
Example quotes

'For my parents, it was really important to have dinner together every night.'

I love the memories of, you know, how your mom or your dad take care of you, you know, feeding you when you're little. That also affects how I do it with my children.

'Yes, because I think we both grew up eating family dinners, different types of dinners, but, I mean, it was something that was important for us, to eat dinners together, and we both grew up where our parents would cook.'

'I've got great cooking skills.'

'They like everything. I mean, that's why I think I enjoy cooking for them, because they really like it, so, yeah.'

'She [my wife] can make anything, I can make things that require like three or four steps.'

I think family dinners were very important, to us, to me growing up, and they remain important.'

'I try to do a lot more mixture, a lot more fruit and vegetables, than was exposed to.'

'[l try to serve] less processed food in general than what we grew up with.'

'[When I was young] we didn't eat together often, or it was, you know, when we did it was always a convenience food or kind of a gross food, like frozen meals usually or take-out Chinese kind of thing.'

'We ate dinner out a lot, like at least three or four times a week, and my parents still do that:

'[My husband's family] was always really big into family dinners, and his mom cooked more Mexican meals, so he enjoys more like the Mexican meals than the rest of us because that's his heritage. And so he brings in that [tradition] and cooking skills.'

I guess, I mean, when I was younger and my cooking skills, they weren't that great. I had to try things a couple of times before I got it right, and the more I did it, the better it was, and so I think that maybe that's why - and I like doing it.'

'But I know that was something that she [my wife] stressed when we had our son and now daughter, we would all sit down and have a dinnertime meal, at least when we were able to:

'I have three brothers, so [in childhood] we'd all kind of be at our own schedule. So I really wanted to change that [as a parent], and that's why I always sit at the kitchen - or, you know, at the dining room table, and then we always talk about what was the worst part of your day, what was the best part of your day, so that we're talking, we're all together.' 
the skills for family meals. Several indicated that they developed cooking skills during adulthood and went beyond their own parents' skills, which made them more confident to prepare a wider variety of foods for their family. For example,

'My mom always laughs and says, "I don't know where your cooking skills came from," but you just learn. You just do and learn and practice and try.' (Mother)

Some also discussed developing meal planning skills, which allowed them to plan ahead for the shopping and food preparation that goes into making a family meal. Alternatively, some participants discussed the important role of the cooking and meal planning skills that their partner brought into their household. For example, one participant said,

'His parents were very good cooks and adventurous with their cooking style, so I think that he has that too and brings that in, where he'll just kind of cook anything and try anything.' (Mother)

The cooking and meal preparation skills described by participants in the 'inconsistent' pattern were quite mixed; some participants described feeling limited by their lack of skills, whereas others noted that they had the skills they needed to plan and prepare meals but did not do so consistently for a variety of other reasons. For example,

'Well, I'm not really much of a cook, so I've got two meals, and part of it is because if I'm cooking, it's because [my husband is] working late, and so I'm watching two kids and trying to put a meal together. So my cooking involves frozen pizza, chicken nuggets, fish sticks, mac and cheese, like really simple food that the kids actually eat.' (Mother)

Further, some participants described feeling like only one adult in their family had the skills needed, which meant that when that person was not available then family meals were not eaten. For example, one participant said,

'My wife's a really good cook, and I could burn water. Yeah, so I - so that's something that I actually want to get better at, because whenever my wife's gone, then I find myself relying on a frozen pizza or macaroni and cheese. ... I want to give my kids a good base for growing up, you know, that they start getting the good habits in. But right now, I don't know. That's kind of my wheelhouse - is easy, unhealthy things, or like eating out at [fast-food locales].' (Father).

\section{Parent priorities}

Many participants who had maintained or carried on the tradition of eating family meals with their own family 
discussed how their desire to maintain this tradition with their family significantly influenced their practice of having family meals as a parent. Several participants in the 'maintainer' pattern also reflected on the types of foods they ate growing up and noted that they have prioritized preparing and serving healthier food options for their children. For example, one participant said,

'And so, you know, I'm trying to break the cycle and give her more variety and things that I was ever exposed to when she is a kid, so I can show my kids and give them a good base for cooking at home and family dinners and things like that.' (Mother)

Another participant stated,

'I would say we try and eat ourselves and feed our daughter less processed kind of foods than we probably ate growing up. I mean, I remember growing up eating a lot of like frozen microwave stuff like for a snack or something. My mom would always cook like a good meal for dinner, but for a snack or lunch when I'm on my own or whatever, you know, and I would just eat a lot of processed junk. I probably drank a lot more pop. We're trying not to do that.' (Father)

Participants within the 'starter' pattern discussed the significance of making family meals a priority; some talked about rearranging work schedules or limiting evening activities, whatever needed to be done to make sure that they preserved this time with their family for most evenings. For example, one participant said,

'I remember having specific like conversations, especially when you're signing your kids up for sports and you're looking at times. If there were options, we'd always sign up for a later time so we could make sure it didn't run into the dinner hour. Now, it could change when they're older, ... but I love our dinnertimes together.' (Mother)

A few parents within the 'starter' pattern talked about the desire to do things differently with their children from the way their parents had done things with them. Some parents discussed this desire broadly; for example, one parent said,

'I've intentionally done things differently [than my parents]' (Mother)

whereas another said,

'So some traditions we're trying to carry on and then other things we're intentionally going against, you know, a reversal of what we grew up with.' (Father)

Other parents were more specific about these differences; for example, one parent discussed trying to limit eating out through meal planning,
'Yeah, I've really tried to change, because my mom was one who never meal planned, and we ate out a lot, tons. [Now] we probably eat out once a week, or we get pizza once a week because it's fun for the kids, and it gives me a break, honestly, once a week. But I have tried to meal plan so we wouldn't be eating out so much - so I would have all the groceries for the week.' (Mother)

For families in the 'inconsistent' meal pattern category, preparing and eating dinner together as a family was not or was inconsistently a top priority. Some participants talked about prioritizing 'relaxed rules' over strict mealtimes together as a family. Many participants in this group discussed general inconsistency in their expectations for mealtimes. As one participant said,

'I find myself being like, "Okay, come sit down. Okay, come sit down. Come sit down." And it's like - so I think it's good for him. I'm like, "Please come up here and eat." But sometimes I'm like, "Whatever. I don't care. Sit under the table." So I'm not super consistent at all.' (Mother)

\section{Discussion}

The current mixed-methods study aimed to expand current knowledge of intergenerational family meal transmission by illuminating how parents' perceptions/ accounts about what influences family meals map onto intergenerational family meal patterns. Specifically, the study used one-on-one qualitative interviews with parents to understand childhood experiences and current contextual factors around family meals across different quantitatively informed categorizations of intergenerational family meal patterns. Findings revealed salient variation within each overarching theme around family meal influences (early childhood experiences, influence of partner, household skills and family priorities) across the different intergenerational family meal patterns ('maintainer', 'starter', 'inconsistent'), in which 'maintainers' had numerous influences that supported the practice of family meals; 'starters' experienced some supports and some challenges; while the 'inconsistent' group experienced many barriers to making family meals a regular practice.

Participants who reported eating frequent family meals during adolescence as well as during adulthood ('maintainers') shared a common set of early childhood experiences that led them to prioritize carrying on the tradition of eating family meals; eating meals with their family during their childhood was expected and routine, as well as an overall positive experience. Many 'maintainers' had partners who either shared a similar tradition of eating family meals, or, at minimum, appreciated the value of adding this type of routine to their current family. Finally, one or 
both partners possessed the skills needed to plan and prepare family meals. Interestingly, several participants in this category discussed their goal to serve healthier food to their children than they ate as a child; for these participants it seemed that because they came into adulthood with the skills needed to prioritize, plan and prepare family meals, they felt capable of working to improve upon the types of foods served during their childhood.

For the participants who did not engage in frequent family meals as children but began to engage in family meals as adults ('starters'), the 'desire to do things differently' with their own family was frequently discussed. Their desire to do things differently led them to prioritize eating meals with their family and to work to overcome barriers, such as lack of cooking or meal planning skills, in order to make this priority a reality. For some, this meant that they taught themselves to cook or spent time developing organizational skills and planning strategies that extended well beyond what they learned from their own parents. For others, their partner played a strong influential role in their ability to begin the tradition of eating family meals by bringing new traditions or skills sets into their relationship that made eating regular family meals more doable.

The group of participants who engaged in family meals only inconsistently or irregularly, both during childhood and with their own families ('inconsistents'), was quite heterogeneous in terms of what kept them from eating regular family meals. Some members of this group placed a high value on family meals, but faced significant barriers, including challenging schedules and limited cooking/meal planning skills, that interfered with making regular family meals a reality. Some of these participants talked about how they would eat family meals when their schedules permitted (e.g. weekend mornings or holidays). Other individuals in the 'inconsistent' meal pattern discussed the role of competing priorities; for example, a few parents talked about prioritizing their child's freedom to eat when and where they wanted, over eating as a family. Overall, this group reported fewer memories or less positive memories of eating family meals as a child, and faced several barriers including inconsistent levels of cooking and food preparation skills and challenging evening schedules.

The extant literature on routines and rituals provides a useful framework to assist with interpretation of the findings from the present mixed-methods study ${ }^{(49)}$. Family routines and rituals both refer to specific, repeated practices that involve two or more family members ${ }^{(49)}$. Yet they are distinct and can be contrasted along the dimensions of communication, commitment and continuity $^{(49)}$. Family routines are characterized by communication that is instrumental (e.g. this is what needs to be done), involve a momentary time commitment and are repeated regularly, but hold special meaning ${ }^{(49)}$. Family rituals, on the other hand, involve symbolic communication (e.g. this is who we are) ${ }^{(49)}$. The time commitment and continuity involved in the performance of rituals moves beyond the current moment and can include repetition across generations ${ }^{(49)}$. Although rituals and routines are distinct, they are often interwoven in daily interactions. Family meals are frequently used as an example of an activity that is not purely a routine or a ritual, but rather contains features of both ${ }^{(50,51)}$. Findings from the present study highlight examples of the blending of ritual and routine and the themes that emerged suggest that the strength of meal-related routines and rituals plays a role in the intergenerational transmission of family meals. For example, it is easy to identify the role that firmly established routines (e.g. food preparation and meal planning skills) and rituals (e.g. value placed on the tradition of meals eaten together) played in the maintenance of regular family meals from one generation to the next, whereas families within the 'inconsistent' intergenerational family meal trajectory described fewer routines and rituals surrounding meals, both during childhood and adulthood. Families in the 'starter' trajectory described working to develop and maintain routines that allowed them to start having regular family meals; perhaps maintenance of these routines over time will allow these family meals within these families to become more of a ritual. Future research on family meals should continue to explore the role of routines and rituals in the maintenance and disruption of intergenerational family meal patterns; and interventions focused on the maintenance of family meals or seeking to encourage families to begin eating together should consider using a routines and rituals framework to guide their programme development.

Findings from our mixed-methods study support and extend prior quantitative work on intergenerational transmission of family meals ${ }^{(31-33,35)}$ by providing rich, detailed information on factors that distinguish how different family meal patterns are passed between generations. That said, it should be noted that although study participants were drawn from a large, population-based sample, this sample is over-represented by white, upper middle class, college educated parents and therefore is not representative of the population at large. Future work should seek to understand if parents of diverse racial/ ethnic and socio-economic backgrounds describe similar factors as influencing intergenerational family meal transmission. Further, given that 'influence of partner' emerged as a salient theme, future research on intergenerational transmission of family meals should consider collecting information from both parents. Finally, the number of participants within each of the family meal pattern groups was relatively small and findings should be interpreted with this limitation in mind. Future research should consider the use of cluster analysis to investigate whether salient sub-themes identified within this small sample exist at a population level. 


\section{Conclusion}

The current study adds significantly to the literature by illuminating specific details about what may influence the transmission of family meal patterns across generations (early experiences, partners, skills, priorities) and identifying specific opportunities for clinicians and public health professionals to intervene to support positive family meal experiences for all families. Specifically, clinical and public health interventions should seek to provide young people with opportunities to learn and practice cooking and meal planning skills during adolescence or young adulthood. Across groups, possessing cooking and planning skills was paramount to making regular family meals a reality; among 'maintainers' these skills were ingrained, allowing them to move towards a focus on improving the healthfulness of meals served, whereas among 'starters' these skills were developed, allowing them to take on the new tradition of having regular family meals, and among the 'inconsistent' group, lack of skills was cited as a barrier. Study findings also suggest the important role that partners play in the development and maintenance of household routines, indicating that future family meal interventions should seek to reach all adults within the home environment. Finally, given the important role that childhood memories played in the transmission of family meals across generations, an effort should be made to reach out to parents for whom family meals during their childhood were not routine or positive, with the goal of helping them to develop an understanding of how and why they might work to incorporate this tradition/ritual into their own family. Primary care providers should consider facilitating a discussion with parents about their former and current family meal routines, as well as educating parents on the health benefits of shared mealtimes, during paediatric primary care visits.

\section{Acknowledgements}

Acknowledgements: The completion of this research would not have been possible without the hard work of student volunteers: Anne Hutchinson, Abbie Lee and Junia Nogueira de Brito. Financial support: This work was supported by the National Institute of Child Health and Human Development (Principal Investigator K.A.L., grant number K23-HD090324-01A1); the National Heart, Lung, and Blood Institute (Principal Investigator D.N.-S., grant number R01HL116892); and the National Institute of Diabetes and Digestive and Kidney Diseases (postdoctoral fellowship M.R.W., Principal Investigator R. Jeffery, grant number T32DK083250). Content is solely the responsibility of the authors and does not necessarily represent the official views of the National Institutes of Health. Conflict of interest: The authors declare that they have no competing interests. Authorship: K.A.L. obtained funding for the study; recruited participants; conducted interviews; coded qualitative data; developed final qualitative themes; conducted quantitative data analysis; wrote the initial draft of the manuscript; and coordinated revisions to the manuscript. M.J.A.U. coded qualitative data; developed final themes; and assisted with writing and thorough review of the manuscript. M.R.W. assisted with the analysis approach and the development of final themes; assisted with quantitative data analysis; and assisted with writing and thorough review of the manuscript. D.N.-S. helped develop the interview guide and the recruitment plan; and assisted with writing and thorough review of the manuscript; she is also the Principal Investigator for the parent study from which participants were recruited, Project EAT. J.O.F. assisted with writing and thorough review of the manuscript. J.M.B. helped develop the interview guide and the recruitment plan; and assisted with writing and thorough review of the manuscript. All authors have read, approved and provided critical revisions to the final manuscript. Ethics of human subject participation: This study was conducted according to the guidelines laid down in the Declaration of Helsinki and all procedures involving human subjects were approved by the University of Minnesota Institutional Review Board. Written or verbal consent was obtained from all subjects. Verbal consent was witnessed and formally recorded.

\section{References}

1. Neumark-Sztainer D, Hannan PJ, Story M et al. (2003) Family meal patterns: associations with sociodemographic characteristics and improved dietary intake among adolescents. J Am Diet Assoc 103, 317-322.

2. Gillman MW, Rifas-Shiman SL, Frazier AL et al. (2000) Family dinner and diet quality among older children and adolescents. Arch Fam Med 9, 235-240.

3. Woodruff SJ, Hanning RM, Lambraki I et al. (2008) Healthy Eating Index-C is compromised among adolescents with body weight concerns, weight loss dieting, and meal skipping. Body Image 5, 404-408.

4. Larson NI, Neumark-Sztainer D, Hannan PJ et al. (2007) Family meals during adolescence are associated with higher diet quality and healthful meal patterns during young adulthood. J Am Diet Assoc 107, 1502-1510.

5. Utter J, Scragg R, Schaaf D et al. (2008) Relationships between frequency of family meals, BMI and nutritional aspects of the home food environment among New Zealand adolescents. Int J Behav Nutr Phys Act 5, 50.

6. Ackard DM, Neumark-Sztainer D (2001) Family mealtime while growing up: associations with symptoms of bulimia nervosa. Eat Disord 9, 239-249.

7. Haines J, Gillman MW, Rifas-Shiman S et al. (2009) Family dinner and disordered eating behaviors in a large cohort of adolescents. Eat Disord 18, 10-24.

8. Leon GR, Fulkerson JA, Perry CL et al. (1994) Family influences, school behaviors, and risk for the later development of an eating disorder. $J$ Youth Adolesc 23, 499-515.

9. Loth K, Wall M, Choi C-W et al. (2015) Family meals and disordered eating in adolescents: are the benefits the same for everyone? Int J Eat Disord 48, 100-110.

10. Loth KA, Neumark-Sztainer D \& Croll JK (2009) Informing family approaches to eating disorder prevention: 
perspectives of those who have been there. Int J Eat Disord 42, 146-152.

11. Neumark-Sztainer D, Eisenberg ME, Fulkerson JA et al. (2008) Family meals and disordered eating in adolescents: longitudinal findings from Project EAT. Arch Pediatr Adolesc Med 162, 17-22.

12. Neumark-Sztainer D, Wall M, Story M et al. (2004) Are family meal patterns associated with disordered eating behaviors among adolescents? J Adolesc Health 35, 350-359.

13. Worobey J (2002) Early family mealtime experiences and eating attitudes in normal weight, underweight and overweight females. Eat Weight Disord 7, 39-44.

14. Birch LL \& Davison KK (2001) Family environmental factors influencing the developing behavioral controls of food intake and childhood overweight. Pediatr Clin North Am 48, 893-907.

15. Calam R \& Waller G (1998) Are eating and psychosocial characteristics in early teenage years useful predictors of eating characteristics in early adulthood? A 7-year longitudinal study. Int J Eat Disord 24, 351-362.

16. Berge JM, Wall M, Hsueh T-F et al. (2015) The protective role of family meals for youth obesity: 10-year longitudinal associations. J Pediatr 166, 296-301.

17. Berge JM, MacLehose RF, Loth KA et al. (2012) Family meals. Associations with weight and eating behaviors among mothers and fathers. Appetite 58, 1128-1135.

18. Fulkerson JA, Story M, Mellin A et al. (2006) Family dinner meal frequency and adolescent development: relationships with developmental assets and high-risk behaviors. $J$ Adolesc Health 39, 337-345.

19. Eisenberg ME, Neumark-Sztainer D, Fulkerson JA et al. (2008) Family meals and substance use: is there a long-term protective association? J Adolesc Health 43, 151-156.

20. Fulkerson JA, Strauss J, Neumark-Sztainer D et al. (2007) Correlates of psychosocial well-being among overweight adolescents: the role of the family. J Consult Clin Psychol 75, 181-186.

21. Eisenberg ME, Olson RE, Neumark-Sztainer D et al. (2004) Correlations between family meals and psychosocial wellbeing among adolescents. Arch Pediatr Adolesc Med 158, 792-796.

22. Flattum C, Draxten M, Horning M et al. (2015) HOME Plus: program design and implementation of a family-focused, community-based intervention to promote the frequency and healthfulness of family meals, reduce children's sedentary behavior, and prevent obesity. Int J Behav Nutr Phys Act 12, 1186.

23. Neumark-Sztainer D, Larson NI, Fulkerson JA et al. (2010) Family meals and adolescents: what have we learned from Project EAT (Eating Among Teens)? Public Health Nutr 13, 1113-1121.

24. National Center on Addiction and Substance Abuse (2011) The Importance of Family Dinners VIII. https://www.cen teronaddiction.org/addiction-research/reports/importance-offamily-dinners-2011 (accessed April 2018).

25. Holt K, Wooldridge NH, Story M et al. (2011) Bright Futures: Nutrition, 3rd ed. Washington, DC: American Academy of Pediatrics.

26. Le Grange D, Lock J, Loeb K et al. (2010) Academy for Eating Disorders position paper: the role of the family in eating disorders. Int J Eat Disord 43, 1-5.

27. Ogata BN \& Hayes D (2014) Position of the Academy of Nutrition and Dietetics: nutrition guidance for healthy children ages 2 to 11 years. J Acad Nutr Diet 114, 1257-1276.

28. Dietz WH \& Stern L (1999) American Academy of Pediatrics Guide to Your Child's Nutrition: Feeding Children of All Ages, 1st ed. New York: Villard Books.

29. Walton K, Kleinman KP, Rifas-Shiman SL et al. (2016) Secular trends in family dinner frequency among adolescents. BMC Res Notes $\mathbf{9}, 35$.
30. Neumark-Sztainer D, Wall M, Fulkerson JA et al. (2013) Changes in the frequency of family meals from 1999-2010 in the homes of adolescents: trends by sociodemographic characteristics. J Adolesc Health 52, 201-206.

31. Fulkerson JA, Larson N, Horning M et al. (2014) A review of associations between family or shared meal frequency and dietary and weight status outcomes across the lifespan. J Nutr Educ Behav 46, 2-19.

32. Watts A, Berge JM, Loth K et al. (2017) The transmission of family food and mealtime practices from adolescence to adulthood: longitudinal findings from Project EAT-IV. J Nutr Educ Behav 50, 141-147.

33. Berge JM, Miller J, Watts A et al. (2018) Intergenerational transmission of family meal patterns from adolescence to parenthood: longitudinal associations with parents' dietary intake, weight-related behaviours and psychosocial wellbeing. Public Health Nutr 21, 299-308.

34. Friend S, Fulkerson JA, Neumark-Sztainer D et al. (2015) Comparing childhood meal frequency to current meal frequency, routines, and expectations among parents. J Fam Psychol 29, 136-140.

35. Trofholz AC, Thao MS, Donley M et al. (2018) Family meals then and now: a qualitative investigation of intergenerational transmission of family meal practices in a racially/ethnically diverse and immigrant population. Appetite 121, 163-172.

36. Malhotra K, Herman AN, Wright G et al. (2013) Perceived benefits and challenges for low-income mothers of having family meals with preschool-aged children: childhood memories matter. J Acad Nutr Diet 113, 1484-1493.

37. Dallos R \& Denford S (2008) A qualitative exploration of relationship and attachment themes in families with an eating disorder. Clin Child Psychol Psychiatry 13, 305-322.

38. Berge JM, MacLehose RF, Meyer C et al. (2016) He said, she said: examining parental concordance on home environment factors and adolescent health behaviors and weight status. J Acad Nutr Diet 116, 46-60.

39. Sobal J (2001) Sample extensiveness in qualitative nutrition education research. J Nutr Educ 33, 184-192.

40. Strauss A \& Corbin J (1994) Grounded theory methodology: an overview. In The SAGE Handbook of Qualitative Research, 4th ed., pp. 273-285 [NK Denzin and YS Lincoln, editors]. Thousand Oaks, CA: SAGE Publications, Inc.

41. Krueger RA \& Casey MA (2014) Focus Groups: A Practical Guide for Applied Research, 5th ed. Thousand Oaks, CA: SAGE Publications, Inc.

42. Miller WL \& Crabtree BF (1999) Doing Qualitative Research, 2nd ed. Thousand Oaks, CA: SAGE Publications, Inc.

43. Broderick CB (1993) Understanding Family Process: Basics of Family Systems Theory. Newbury Park, CA: SAGE Publications, Inc.

44. Elo S \& Kyngäs H (2008) The qualitative content analysis process. J Adv Nurs 62, 107-115.

45. Miles MB, Huberman AM \& Saldana J (1984) Qualitative Data Analysis: A Sourcebook. Beverly Hills, CA: SAGE Publications, Inc.

46. Guba EG \& Lincoln YS (1989) Fourth Generation Evaluation. Newbury Park, CA: SAGE Publications, Inc.

47. Denzin NK \& Lincoln YS (editors) (2011) The SAGE Handbook of Qualitative Research, 4th ed. Thousand Oaks, CA: SAGE Publications, Inc.

48. Patton MQ (1990) Qualitative Evaluation and Research Methods, 2nd ed. Newbury Park, CA: SAGE Publications, Inc.

49. Fiese BH, Tomcho TJ, Douglas $\mathrm{M}$ et al. (2002) A review of 50 years of research on naturally occurring family routines and rituals: cause for celebration? J Fam Psychol 16, 381-390.

50. Fiese BH, Hammons A \& Grigsby-Toussaint D (2012) Family mealtimes: a contextual approach to understanding childhood obesity. Econ Hum Biol 10, 365-374.

51. Fiese BH, Foley KP \& Spagnola M (2006) Routine and ritual elements in family mealtimes: contexts for child well-being and family identity. New Dir Child Adolesc Dev 2006, 67-89. 